\title{
Correction to: Laws, Models, and Theories in Biology: A Unifying Interpretation
}

\author{
Pablo Lorenzano and Martín Andrés Díaz
}

\section{Correction to:}

Chapter 10 in: L. Baravalle, L. Zaterka (eds.), Life and Evolution, History, Philosophy and Theory of the Life Sciences 26, https://doi.org/10.1007/978-3-030-39589-6_10

The published version of the book has missed to include the correct figures in chapter 10 .

This error has been corrected, and the Figures 10.3, 10.5, 10.6 and 10.7 have been updated in the book.

Fig. 10.3 Theory-net

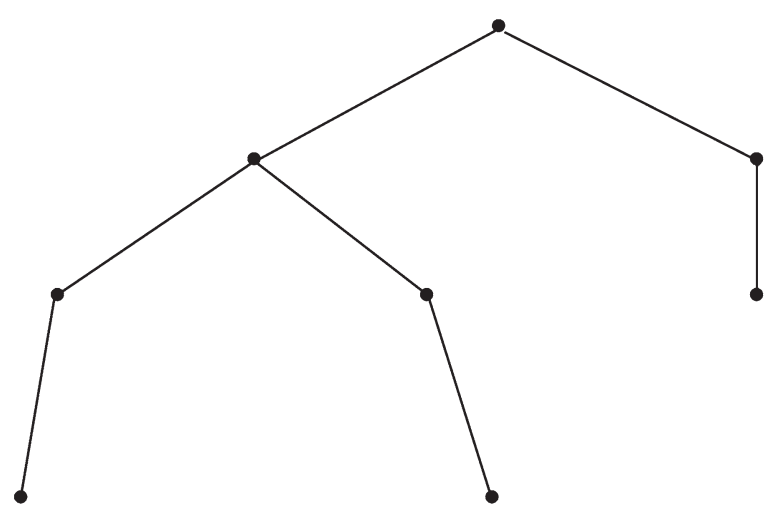

The updated online version of this chapter can be found at https://doi.org/10.1007/978-3-030-39589-6_10 
Fig. 10.5 Theory-net with only one theory-element

Fig. 10.6 Model in search of a fundamental law/ guiding principle

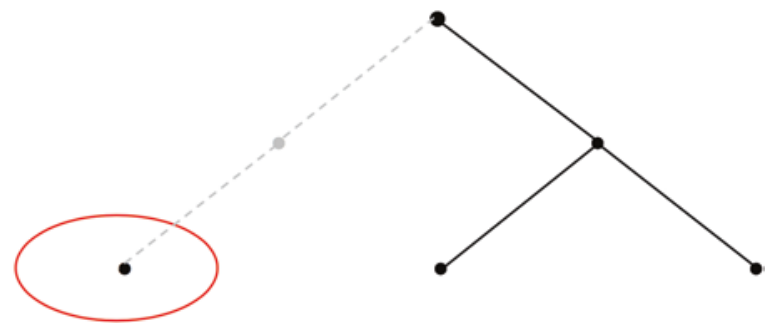

Fig. 10.7 A law from which a theory-net is developed

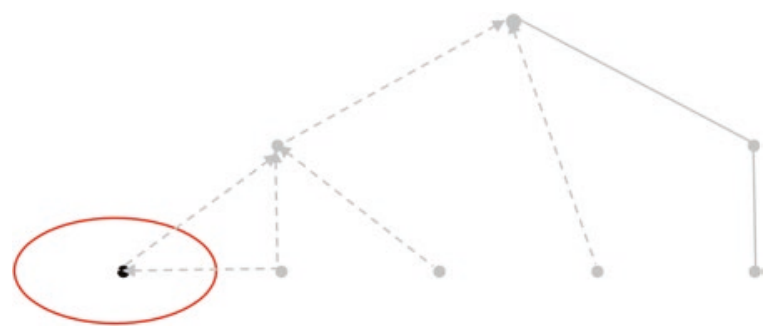

